\title{
A propósito de las categorías de modo de producción y formación económica social
}

\author{
About the categories of production mode and social economic formation
}

\author{
Anabella Gluj*
}

Resumen: El presente artículo tiene como propósito revisar el uso de las categorías de modo de producción y formación económica social en la obra de Karl Marx, atendiendo a las divergencias con las lecturas comúnmente difundidas y empleadas de las mismas. Se discute principalmente con las nociones que asocian al modo de producción con un objeto teóricoabstracto, que muestra de manera "pura" aquello que en la formación económica social se ve de manera histórica y concreta. Dicha lectura, suele vincularse a aquella que restringe a los modos de producción a una correspondencia entre relaciones sociales de producción y fuerzas productivas, en tanto base económica de la sociedad. Mientras que, tal visión entiende a las formaciones económica-sociales como articulación de modos de producción. A lo largo del presente trabajo, se contrastará la lectura canonizada con las formulaciones del propio Marx, con el objetivo de revalorizar sus aportes a doscientos años de su nacimiento.

Palabras clave: Marx; modo de producción; formación económica social; dialéctica

\begin{abstract}
The purpose of this article is to review the use of "mode of production" and "social formation" in Karl Marx's work, taking into account the differences with the way these are now commonly used.

It is discussed here, the ideas that associate mode of production with a theoretical-abstract object and social formation with an historical and concrete one. This interpretation usually restricts the use of "modes of production" to a correspondence between relations of production and productive forces, as the economic basis of society. Whereas, such vision understands economic-social formations as articulation of modes of production. Throughout the present article, this canonized reading will be contrasted with Marx's work, with the aim of revaluing his contributions on the 200th anniversary of his birth.
\end{abstract}

Keywords: Marx; mode of production; social formation; dialectic

Recibido: 15 septiembre 2018 Aceptado: 7 diciembre 2018

\footnotetext{
* Argentina, Profesora de Enseñanza Media y Superior en Historia, Facultad de Filosofía y Letras, Universidad de Buenos Aires.

Correo electrónico: anigluj@gmail.com
} 


\section{Introducción}

Las múltiples lecturas e interpretaciones de la obra de Karl Marx han suscitado numerosas polémicas teórico-políticas. A doscientos años de su nacimiento, las discusiones en torno de las reflexiones de Marx han recobrado actualidad; a la vez que se revitalizaron viejos debates que ponen de relieve la centralidad de sus aportes para comprender el mundo actual.

En el presente artículo, nos proponemos ahondar en una polémica aún abierta en torno a dos categorías claves dentro del marxismo: modo de producción y formación económica social. Las mismas han sido conceptualizadas de manera diversa; en muchos casos incluso han sido consideradas sinónimos, dando lugar no sólo a equívocos, sino a interpretaciones divergentes de distintos procesos históricos y a posicionamientos políticos opuestos. Que aún en nuestros días no haya claridad sobre el empleo de tales categorías sustanciales dentro del materialismo histórico, nos invita a reflexionar y volver una vez más sobre los escritos del propio Marx, contrastándolos con las lecturas que de ellos se han hecho en los trabajos históricos y teóricos posteriores.

En este sentido, es importante destacar que los principales debates en torno a estas categorías se han dado durante los años 60' y 70,' en un contexto particular de agudización de la lucha de clases a nivel mundial. En esa coyuntura, se comprende el especial interés por indagar en problemáticas como las condiciones de los modos de producción y su posibilidad de transformación, la apertura de fases transicionales, el vínculo entre la lucha de clases y las condiciones materiales, entre otros.

Si bien han proliferado ampliamente los estudios históricos vinculados con los modos de producción precapitalistas a partir de estos debates de los años $60^{\prime}$ y 70', la polémica sobre el sentido de las categorías de modo de producción y formación económico social ha sido abandonada. En esta línea, han sobresalido y primado en las investigaciones históricas posteriores, las visiones estructuralistas cuyas lecturas en alguna medida, han sido generalizadas ante la cancelación del debate.

En estas páginas nos proponemos replantear aquellas visiones canonizadas -principalmente la estructuralista- y retomar la discusión de ambas categorías. En las formulaciones dominantes la formación económica social, entendida como una categoría concreta e histórica, se contrapone con la de modo de producción, en tanto objeto teórico y abstracto, y por lo tanto "puro"1. Allí se observa una oposición entre lo abstracto y lo concreto que traduciría la dualidad entre lo teórico y lo histórico. Como tendremos oportunidad de desarrollar, esta formulación se aleja de la concepción dialéctica presente en Marx.

Esta dicotomía entre abstracto y concreto está vinculada, a su vez, con una visión generalizada que reduce al modo de producción a la base material, a la esfera "económica". Se trata de una combinatoria de ciertas relaciones de producción y un determinado grado de desarrollo de las fuerzas productivas ${ }^{2}$. Esta lectura, que compartimenta la totalidad en esferas, está presente en la gran mayoría de las interpretaciones, y merece ser rediscutida. Del mismo modo, resulta necesario revisar los planteos de algunos autores que matizan esta lectura, al proponer la correspondencia de un modo de producción con una determinada relación de explotación ${ }^{3}$

\footnotetext{
${ }^{1}$ Ver: Louis Althusser, Étienne Balibar, Para leer El Capital, México, Siglo XXI, 2004; Perry Anderson, Transiciones de la antigüedad al feudalismo, México, Siglo XXI, 2007; Marta Harnecker, Los conceptos elementales del materialismo bistórico, Buenos Aires: Siglo XXI, 200; . Barry Hindess, Paul Hirst, Los modos precapitalistas de producción $n_{s}$ Barcelona: Ediciones Península, 1979; Eric Hobsbawm, "Introducción" en Marx, Karl. Formaciones económicas precapitalistas, México: Siglo XXI, 2009; Nicos Poulantzas, Poder politico y clases sociales en el Estado capitalista, México: Siglo XXI, 2007

2 Ver: Maurice Godelier, Economía, fetichismo y religión en las sociedades primitivas, Madrid: Siglo XXI, 1974; Hindess, Hirst, , op.cit, Hobsbawm, , op.cit.

${ }^{3}$ Ver: Robert Brenner, "Estructura de clases agraria y desarrollo económico en la Europa preindustrial" en Aston, T. H y Philpin, C.H. E (comps) El debate Brenner, Barcelona, Crítica, 1987; Maurice Dobb, Estudios sobre el desarrollo del capitalismo, México, Siglo XXI, 2005; Ellen Meiksins Wood, Democracia contra capitalismo, México: Siglo XXI, 2000; Charles Post, The American Road to Capitalism, studies in class-structure, economic development, and political conflict, 1620-1877, Boston: Historical Materialism Series 28, Brill, 2011
} 
Si la noción de modo de producción ha dado lugar a esta diversidad de abordajes, la de formación económica social no resulta menos polémica. La visión que plantea esta categoría como expresión concreta e histórica, suele complementarse con aquella que entiende a la formación económica social como articulación de modos de producción ${ }^{4}$. Al comprenderlo de este modo, muchos de estos autores emplean la categoría de formación económica para referirse a expresiones nacionales de un modo de producción, hablando por ejemplo de formación económica inglesa, francesa, estadounidense, etc. ${ }^{5}$ En esta línea, algunos trabajos limitan la operatividad de la formación económica social al estudio de los procesos transicionales, retomando algunas apreciaciones de Lenin ${ }^{6}$

Al ser tan vasta y compleja la polémica, y dado que, sus participantes reivindican para sí la posición original de Marx, es ineludible volver a sus planteos. Para ello es menester advertir que los estudios específicos de Marx sólo cobran sentido dentro de la totalidad de su obra; en palabras de Pierre Vilar:

No solo para la «marxología», sino también para la epistemología, y ante todo para la historia, es perjudicial que casi todas las ediciones de Marx aíslen las obras, desordenando la cronología, distinguiendo entre sus contenidos y sus «géneros» (obras «económicas», «políticas», «filosóficas», etc.) mientras que la fuerza de Marx está en tratar los problemas no bajo todos los aspectos, sino a través de todos los aspectos relacionados entre sí, surgiendo precisamente sus lecciones de esas combinaciones en sus adquisiciones sucesivas ${ }^{7}$

En esta línea, con la finalidad de contribuir a una mejor comprensión de las contribuciones de Marx, ordenaremos la argumentación en diversos ejes. En primer lugar, indagaremos en las interpretaciones dominantes sobre modo de producción, para contraponer una nueva mirada sobre la obra de Marx que procure evitar todo tipo de reduccionismos. En segundo lugar, analizaremos la categoría de formación económica social, principalmente examinando los debates en torno de la articulación de modos de producción y las fases transicionales. Por último, propondremos unas breves reflexiones sobre la dialéctica y la visión de la historia planteada por Marx.

\section{Modo de producción como modo de vida}

Comencemos por indagar en los usos de la categoría de modo de producción. Como hemos señalado, una de las visiones más difundidas establece una correspondencia entre relaciones sociales de producción y fuerzas productivas, identificando el modo de producción con la "base económica" de la sociedad. Sin embargo, lejos de esta formulación parcial, el propio Marx propone un abordaje del modo de producción en tanto totalidad, en tanto modo de vida. Podemos verlo claramente en La Ideología Alemana:

El modo como los hombres producen sus medios de vida depende, ante todo, de la naturaleza misma de los medios de vida que encuentran en forma acabada y que pueden ser reproducidos. Este modo de producción no debe considerarse solamente en cuanto es la reproducción de la existencia física de los individuos. Es ya, más bien, un modo determinado de la actividad de estos individuos, un modo determinado de manifestar su vida, un modo de vida determinado de los mismos. Tal como los

\footnotetext{
${ }^{4}$ Ver Althusser, Balibar, op.cit;; Anderson, op.cit; Godelier, op.cit.; Hindess, B. Hirst,P, op.cit; Poulantzas, op.cit.

5 Ver: Anderson, op.cit; Harnecker, op.cit; Nicos Poulantzas, Las clases sociales en el capitalismo actual, México: Siglo XXI, 2016

${ }^{6}$ Christine Glucksman, "Modo de producción, formación económica y social, y teoría de la transición a propósito de Lenin", en Luporini, C; Sereni, E., El concepto de "formación económico-social", Buenos Aires, Ediciones Pasado y Presente, Siglo XXI, 1973

7 Pierre Vilar, Economía, derecho, historia, Barcelona, Ariel, 1983, p. 178
} 
individuos manifiestan su vida, así son. Lo que son coincide, por consiguiente con su producción, tanto con lo que producen como con el modo cómo producen ${ }^{8}$

Aquellos que visualizan una ruptura entre un "Marx joven" y un "Marx maduro" podrían argumentar que este pasaje no da cuenta de su pensamiento acabado como se refleja en El Capital; sin embargo, justamente en esta obra nos encontramos con formulaciones similares:

Como todos sus predecesores, el proceso capitalista de producción se opera bajo determinadas condiciones materiales que, empero, son al mismo tiempo portadoras de determinadas relaciones sociales que los individuos contraen en el proceso de reproducción de su vida. Aquellas condiciones, como estas relaciones, son por un lado supuestos, y por el otro resultados y creaciones del proceso capitalista de producción, el cual las produce y reproduce ${ }^{9}$

En este pasaje, observamos una visión del modo de producción asociada al modo de vida, a todas aquellas relaciones que hacen a la sociedad en tanto totalidad. Marx enfatiza tanto la historicidad del modo de producción, como su implicancia en la reproducción de la vida social. El modo de producción existe sólo, por lo tanto, en la producción y reproducción de sus condiciones materiales. Es decir, en tanto reproducción de sus contradicciones. Las mismas están basadas en el propio antagonismo de toda sociedad de clases. La lógica de reproducción de cada modo de producción es la clave para comprender su dinámica: son aquellas tendencias históricas que hacen a la reproducción de esa sociedad, la cual nunca es idéntica a sí misma y, de este modo es posible indagar en las fases o momentos del modo de producción.

Desde esta perspectiva, en la centralidad del modo de producción como modo de vida y como categoría histórica se pone de manifiesto su propia complejidad:

Pero el análisis científico del modo capitalista de producción demuestra, a la inversa, que es un modo de producción de índole particular, de una determinación histórica específica; que al igual que cualquier otro modo determinado de producción presupone, como condición histórica suya, una fase dada de las fuerzas productivas sociales y de sus formas de desarrollo, condición que a su vez es resultado y producto histórico de un proceso precedente y del cual parte el nuevo modo de producción como de su base dada; que las relaciones de producción correspondientes a ese modo de producción específico e históricamente determinado — relaciones que los hombres contraen en el proceso de su vida social y en la generación de su vida social — tienen un carácter específico, histórico y transitorio, y que, finalmente, las relaciones de distribución son esencialmente idénticas a esas relaciones de producción, un reverso de las mismas, de manera que ambas comparten el mismo carácter históricamente transitorio $^{10}$

La correspondencia mecánica entre fuerzas productivas y relaciones sociales de producción que se ha asumido como un canon por numerosos investigadores, entendemos que no encuentra fundamento en los escritos del propio Marx. Por el contrario, el vínculo entre relaciones sociales de producción y fuerzas productivas es complejo y dialéctico ${ }^{11}$, de modo que estos elementos si bien son determinaciones

\footnotetext{
${ }^{8}$ Karl Marx, Friedrich Engels, "Feuerbach, contraposición entre la concepción materialista y la idealista (Capítulo I de La Ideología Alemana)", Obras Escogidas, Tomo IV, Buenos Aires: Ciencias del Hombre, 1973, p. 15.

${ }^{9}$ Karl Marx El Capital, Tomo III, Vol. 8, México: Siglo XXI, 2009, p. 1042

${ }^{10}$ Ibid. p. 1114

$11 \mathrm{Al}$ respecto, proponemos una lectura que se aleja de la comprensión de relaciones sociales de producción en tanto relaciones de propiedad y de fuerzas productivas como desarrollo tecnológico. Por el contrario, las relaciones sociales de producción involucran aquellas relaciones históricas que hacen a la estructuración social, incluyendo las relaciones de propiedad, pero
} 
relevantes de los modos de producción tampoco pueden ser subsumidos a factores meramente "económicos".

La visión estructuralista que compartimenta lo real en esferas diferenciadas, siendo la totalidad una combinatoria jerarquizada de las mismas, amerita ser revisada a la luz de las propias formulaciones de Marx. En este sentido, hasta en el propio Prólogo a la Contribución... -quizás la obra más citada por quienes sostienen esta interpretación- también nos encontramos con que "el modo de producción de la vida material determina [bedingen] el proceso social, político e intelectual de la vida en general" 12 . Es decir, nuevamente se concibe al modo de producción en tanto modo de vida, estableciéndose un claro paralelismo con el pasaje de La Ideología Alemana anteriormente citado: "Tal como los individuos manifiestan su vida, así son. Lo que son coincide, por consiguiente con su producción, tanto con lo que producen como con el modo cómo producen"13. Es decir, se evidencia el problema del ser y la manifestación del ser; la conceptualización del modo de producción en tanto modo de vida, permite dar cuenta de esto, aprehendiendo la totalidad en sus múltiples determinaciones y en su desenvolvimiento histórico contradictorio.

Los peligros de las aproximaciones simplificadoras y reduccionistas ya habían sido advertidos por Marx y Engels, cuya preocupación por la vulgarización del materialismo histórico que importan las lecturas economicistas o deterministas se plasma en la abundante correspondencia sostenida por ambos. $\mathrm{Al}$ respecto, en una carta a Bloch, Engels aclaraba:

Según la concepción materialista de la historia, el elemento determinante de la historia es en última instancia la producción y la reproducción de la vida real. Ni Marx ni yo hemos afirmado nunca otra cosa que esto; por consiguiente, si alguien lo tergiversa transformándolo en la afirmación de que el elemento económico es el único determinante, lo transforma en una frase sin sentido, abstracta y absurda ${ }^{14}$

En la misma línea, retomamos las palabras de A. Labriola al respecto:

Se equivocan los que, llamándola interpretación económica de la historia, creen abrazarlo todo (...) Estamos aquí ante la concepción orgánica de la historia. La total unidad de la vida social (...) En la economía misma (quiero decir el ordenamiento de becho, y no la ciencia acerca del mismo) que se resuelve en el curso de un proceso (...) No se trata, en suma, de extender el sedicente factor económico abstractamente aislado a todo el resto, como imaginan nuestros adversarios, sino que se trata ante todo de concebir históricamente la economía y de explicar los otros cambios históricos mediante $\operatorname{esos}^{15}$

En este sentido, contra el "sedicente" factor económico reconocemos en el modo de producción la totalidad entendida como modo de vida. Contra la compartimentación del todo social, proponemos una mirada atenta a las determinaciones, a las tendencias que hacen a la reproducción y a la lucha de

también las formas de explotación, las organización y control del proceso inmediato de producción, entendidas en el marco del desenvolvimiento de la propia lucha de clases y la lógica que hace a la reproducción del modo de producción. En este sentido, ambas categorías son indisociables. Por su parte, las fuerzas productivas las entendemos como una relación, mediada por la lucha de clases, comprendiendo todo aquello que aumenta históricamente la capacidad humana de producir habiendo en su interior una variada gama de elementos (condiciones naturales, división del trabajo, maquinaria, obreros especializados), que abstraídos y separados unos de otros no sólo se anulan conceptualmente, sino que carecen de existencia real en la producción. Las fuerzas productivas se presentan de manera fetichizada en el capitalismo, como fuerzas del capital, ajenas a los trabajadores, como fuerza que los oprime, lo cual suele traducirse teóricamente también en una fetichización de las mismas asociadas a la tecnología.

${ }^{12}$ Karl Marx Contribución a la Crítica de la Economía Política, México, Siglo XXI, 2011a, p. 4

${ }_{13}$ Marx, Engels, op.cit, 1973a, p. 15.

${ }^{14}$ Karl Marx, Friedrich Engels, Correspondencia, Buenos Aires: Cartago, 1973b , p. 379

15 Antonio Labriola, En memoria del Manifiesto Comunista, 1964, p. 54-59 
clases capaz de transformarlas. De este modo, consideramos que el modo de producción no representa una categoría abstracta, sino concreta, no "económica" sino del todo social, no estática ni típico-ideal, sino histórica.

$\mathrm{Al}$ respecto, como mencionábamos, en El Capital se condensa este último aspecto: la historicidad de los modos de producción y la posibilidad de transformación histórica. Aquí aparece la concepción que Marx tiene de la historia, expresada de manera cabal en el célebre fragmento de El Dieciocho Brumario de Luis Bonaparte: "los hombres moldean su propia historia, pero no lo hacen libremente, influidos por condiciones que ellos han elegido, sino bajo las circunstancias con que se tropiezan inexorablemente, que están ahí, transmitidas por el pasado. La herencia de todas las generaciones muertas acosa la mente de los vivos como una pesadilla" ${ }^{16}$. El modo de producción, la propia estructuración material determina la forma que adopta la lucha de clases, mientras que, su resolución dependerá de la correlación de fuerzas y del desarrollo de la propia lucha. Determinación material, sin mecanicismo determinista.

Ahora bien, en el intento saludable de superar los reduccionismos, lecturas más recientes han caído en otro tipo de simplificaciones. Entre ellas, destacamos la visión que asimila a los modos de producción a una relación social de producción dominante: siendo esclavista toda sociedad signada por el trabajo esclavo, feudal toda sociedad determinada por el trabajo servil y capitalista aquella dada por el trabajo asalariado, lectura evidenciada por ejemplo en el reciente trabajo de Charles Post ${ }^{17}$.

Ante esta lectura, proponemos en contraposición, retomando la concepción de modo de producción en tanto modo de vida y totalidad histórica contradictoria, ponderar la lógica que hace a la reproducción. En otras palabras, comprendemos que el modo de producción basado en una determinada lógica de reproducción social, da sentido histórico a las distintas formas de explotación reales existentes. La cuestión en todo caso radica, en indagar cuál es la lógica de reproducción que hace a la totalidad y, con ello advertir el tipo de relación de explotación al que el devenir histórico del modo de producción tiende a generalizar.

Al respecto, amerita retomar los aportes de J. Banaji que ha precisado la distinción entre relaciones sociales de producción y formas de explotación del trabajo:

Las relaciones de producción no se reducen simplemente a formas de explotación, debido a que los modos de producción abarcan una gama más amplia de relaciones que las del proceso inmediato de producción y porque el despliegue del trabajo, la organización y el control del proceso de trabajo "se correlaciona" históricamente y de complejos modos con las relaciones de producción ${ }^{18}$ [Traducción propia $]^{19}$

Adhiriendo a estas palabras de Banaji, añadimos que la reducción del modo de producción a una forma de explotación, implica una visión típico-ideal de la categoría, en tanto parte de la abstracción de una característica para establecer un modelo puro. Es fundamental entender la historicidad de los modos de producción, atendiendo, entre otras cosas, a sus diferentes fases. En este sentido se trata de reconocer el proceso histórico de subsunción de las distintas formas de explotación a una determinada lógica de reproducción y por lo tanto, la progresiva generalización de relaciones sociales de producción

\footnotetext{
${ }^{16}$ Karl Marx, El Dieciocho Brumario de Luis Bonaparte, Buenos Aires: Andrómena, 2004, p. 17

17 Post, op.cit.

Para un desarrollo de tal aspecto de la obra de C. Post puede consultarse: Anabella Gluj, El Marxismo Politico: aportes y problemas para el estudio de las relaciones internacionales y el desarrollo del capitalismo en Estados Unidos, Mar del Plata: XVI Jornadas Interescuelas/departamentos de Historia, 2017. Disponible en:

https://interescuelasmardelplata.files.wordpress.com/2017/09/54-gluj.pdf

18 Jairus Banaji, Theory as History. Essays on Modes of production and exploitation, Boston, Brill, 2010, p. 41

19 "Relations of production are simply not reducible to forms of exploitation, both because modes of production embrace a wider range of relationships than those in their immediate process of production and because the deployment of labour, the organisation and control of the labour-process 'correlates' with historical relations of production in complex ways"
} 
determinadas. Marx se detiene en este aspecto, especialmente para señalar la especificidad de los momentos de génesis y desarrollo:

Esto es, a sus supuestos históricos, que precisamente en cuanto tales supuestos históricos pertenecen al pasado y por tanto a la historia de su formación, pero de ningún modo a su historia contemporánea, es decir, no pertenecen al sistema real del modo de producción dominado por el capital. (...)Las condiciones y supuestos del origen, de la génesis del capital, suponen precisamente que el capital aún no es, sino que tan sólo llega a ser; desaparecen, pues, con el capital real, con el capital que pone él mismo, partiendo de su realidad, las condiciones de su realización ${ }^{20}$

La misma mirada aporta Lenin en El desarrollo del capitalismo en Rusia:

Cabe agregar que en nuestras obras se comprende a menudo con excesiva rigidez la tesis teórica de que el capitalismo requiere un obrero libre, sin tierra. Eso es del todo justo como tendencia fundamental, pero en la agricultura el capitalismo penetra con especial lentitud y a través de formas extraordinariamente diversas ${ }^{21}$

Es decir que, identificar en la forma de explotación el elemento constitutivo de un modo de producción, imposibilita ver la complejidad presente en los procesos de la génesis, así como el despliegue histórico que implica la generalización de determinada lógica de reproducción y de determinadas relaciones sociales de producción.

Fueron necesarios siglos hasta que el trabajador "libre", por obra del modo de producción capitalista desarrollado, se prestara voluntariamente, es decir, se viera socialmente obligado, a vender todo el tiempo de su vida activa, su capacidad misma de trabajo, por el precio de sus medios de subsistencia habituales ${ }^{22}$

Marx claramente identifica en el caso del modo de producción capitalista la importancia de los procesos de subordinación de otras relaciones de explotación a la lógica del capital como elemento central de la fase de génesis. Esto se pierde de vista en las lecturas que le quitan su contenido histórico a las estructuras que analizan ${ }^{23}$. A su vez, ese tipo de análisis imposibilita ver la complejidad de la totalidad, la coexistencia de formas de explotación subordinadas a una lógica de reproducción en una totalidad determinada. Aquí radica una de las claves para comprender la categoría de formación económica social que desarrollaremos a continuación.

\section{Formación económica social: la complejidad puesta en relieve}

Llegados a este punto, se nos plantea la necesidad de precisar qué entendemos por formación económica social. Con respecto a ésta, suele considerarse que la misma fue empleada por Marx de un modo no sistemático y que comenzó a tener un rol fundamental dentro del marxismo a partir de la interpretación de Lenin ${ }^{24}$. Luego, como hemos mencionado, el estructuralismo ha dicotomizado y

${ }^{20}$ Karl Marx, Elementos fundamentales para la crítica de la economía politica (Grundrisse) 1857-1858, México: Siglo XXI, 2009b, p. 4201

21 Vladimir I. Lenin, El desarrollo del capitalismo en Rusia, En: Obras completas, Vol. III. Buenos Aires, Cártago, 1957, p 117.

${ }^{22}$ Karl Marx, El Capital, Tomo I, Vol. 1, Buenos Aires: Siglo XXI, 2008, p. 327

${ }^{23}$ Lo mismo se observa en el caso de los países atrasados cuyo desarrollo, como evidenció León Trotsky, resulta desigual y combinado. Dar cuenta de la coexistencia de formas "arcaicas" con "modernas" mina contra todo tipo de visión etapista de la historia, evidenciando la complejidad de la misma en su devenir y el rol fundamental de la lucha de clases en la misma.

${ }^{24}$ Vladimir I. Lenin, ¿Quiénes son los "amigos del pueblo" y cómo luchan contra los socilademócratas?, Buenos Aires: Editorial Ateneo, 1973 
opuesto tal categoría a la de modo de producción. En esta línea, desde finales de los años 60 del pasado siglo se han producido una serie de debates, entre los cuales se destaca la polémica publicada en Cuadernos Pasado y Presente de la que han participado numerosos investigadores ${ }^{25}$.

La discusión giró en torno de tres ejes. En primer lugar, el sentido de la articulación de modos de producción. En segundo término, el problema de la transición y por último, el carácter abstracto o concreto de la categoría -vinculado en este caso con la contraposición estático/dinámico. La posición que asumen los distintos especialistas está estrechamente condicionada por el modo en que cada uno de ellos comprende las categorías en debate; en muchos casos, la formación económico social ha sido asumida como un sinónimo de modo de producción. Sin embargo, las formulaciones del propio Marx nos obligan a revisar esta asimilación; en la medida en que ambas categorías dan cuenta de la totalidad, son concretas e históricas, concebidas como "proceso de historia natural"26.

Si la categoría de modo de producción visibiliza la totalidad en su desenvolvimiento histórico, en tanto la lógica de reproducción del mismo determina todos los aspectos de la vida; la formación económica-social permite dar cuenta de la totalidad desde otra perspectiva, en la medida en que contribuye a ver la complejidad histórica. Así es posible distinguir la existencia de relaciones sociales o de explotación cuya forma se reconoce con un modo de producción, pero su contenido está dado por la totalidad. Esto puede observarse en los Grundrisse:

En todas las formas de sociedad existe una determinada producción que asigna a todas las otras su correspondiente rango [e] influencia, y cuyas relaciones por lo tanto asignan a todas las otras el rango y la influencia. Es una iluminación general en la que se bañan todos los colores y [que] modifica las particularidades de éstos. Es como un éter particular que determina el peso específico de todas las formas de existencia que allí toman relieve ${ }^{27}$

Esta cita es usualmente utilizada por quienes conciben las formaciones económicas sociales como articulación de modos de producción; sin embargo, proponemos que debe leerse desde otra perspectiva. Entendemos que plantear una totalidad como articulación de otras totalidades resulta confuso y teóricamente débil. Por el contrario, planteamos que aquello que pone en evidencia Marx es la transformación del contenido de una totalidad en la cual se inscribe una forma social particular: "se ve aquí cómo incluso categorías económicas correspondientes a épocas anteriores de la producción adoptan sobre la base del modo capitalista de producción, un carácter histórico específicamente diferente" 28.

Lo mismo puede observarse en otro pasaje: "además, como la sociedad burguesa no es en sí más que una forma antagónica de desarrollo, ciertas relaciones pertenecientes a formas de sociedad anteriores aparecen en ella sólo de manera atrofiada o hasta disfrazadas" 29 .

En esta línea, se comprende, por ejemplo, la existencia de relaciones de explotación esclavistas enmarcadas en una totalidad capitalista que les imprime un contenido distinto. Esto es lo que nos permite analizar la categoría de formación económica social. Los aportes de R. Bartra son de sumo interés en este sentido:

El concepto de formación económica de la sociedad expresa una realidad global mediante una mayor disociación de los términos de la síntesis particular-general; por esta razón el concepto permite reconocer los nexos históricos y lógicos de las partes de un todo, permite ubicar las particularidades determinadas por el todo general, y las

\footnotetext{
${ }^{25}$ Cesare Luporini, Emilio Sereni, El concepto de "formación económico-social", Buenos Aires: Ediciones Pasado y Presente, Siglo XXI, 1973

${ }^{26}$ Marx, op.cit, 2008, p. 8

27 Marx, op.cit., 2009b, p. 28

${ }^{28}$ Karl Marx, El Capital Libro I Capitulo VI (inédito), México, Siglo XXI, 2011b, p. 110

${ }^{29}$ Marx, op.cit., 2009b, p. 26
} 
condiciones de generalización de las particularidades de las diferentes formas sociales. ${ }^{30}$

Estamos por lo tanto ante una categoría concreta, que da cuenta de la complejidad de la totalidad y su desenvolvimiento histórico, en contraste con la visión estructuralista de articulación de modos de producción. Nos queda por desandar, entonces, su función para dar cuenta de los procesos transicionales. Al respecto se han producido sucesivos debates durante el siglo pasado, signados principalmente por el problema de la transición al socialismo. El pasaje de un modo de producción a otro como problema teórico- político se puede rastrear en la obra de Marx y como es de suponerse, principalmente en la de Lenin.

Ahora bien, ¿qué caracteriza a una fase transicional? ¿Qué abre una fase de este tipo? En El Capital, Marx afirma que "el desarrollo de las contradicciones de una forma histórica de producción, no obstante, es el único camino histórico que lleva a la disolución y transformación de la misma"31. Es decir, como sostiene en las Formen: "Hasta cierto punto, reproducción. Luego se trastrueca en disolución"32. La reproducción contradictoria de la totalidad abre paso a su disolución. El camino es histórico en palabras de Marx, y por lo tanto tenemos situaciones como las descriptas por Lenin que evidencia el momento transicional al comunismo en el cual prevalecen y coexisten dos lógicas de reproducción:

Teóricamente, no cabe duda de que entre el capitalismo y el comunismo existe cierto período de transición. Este período no puede dejar de reunir los rasgos o las propiedades de ambas formaciones de la economía social, no puede dejar de ser un período de lucha entre el capitalismo agonizante y el comunismo naciente; o en otras palabras: entre el capitalismo vencido, pero no aniquilado, y el comunismo ya nacido, pero muy débil aún ${ }^{33}$

La categoría de formación económica social nos permite indagar en este tipo de momentos, en los cuales no hay una lógica de reproducción dominante de la totalidad; sino que por el contrario coexisten de manera contradictoria una "agonizante" y una "naciente". Tenemos pues, una categoría central del marxismo que da cuenta del método dialéctico y una visión de la historia en muchas ocasiones erróneamente interpretada como evolucionista y determinista, ambas cuestiones que ameritan una reflexión aparte.

\section{Notas sobre el método dialéctico y la visión de la historia en la obra de Marx}

Como ya hemos desarrollado en los apartados precedentes, una lectura difundida le asigna a la categoría de modo de producción un contenido abstracto, mientras que a la de formación económica social, una significación concreta. Al respecto, es necesario clarificar algunos aspectos del método dialéctico: el modo de investigación y el modo de exposición propuesto por Marx. Para ello, entendemos fundamental retomar algunos pasajes de los Grundrisse:

Parece justo empezar por lo real y lo concreto, por el supuesto efectivo; (...) tendría una representación caótica del conjunto y, precisando cada vez más, llegaría analíticamente a conceptos cada vez más simples: de lo concreto representado llegaría a abstracciones cada vez más sutiles hasta alcanzar las determinaciones más simples. Llegando a este punto, habría que reemprender el viaje de retorno, (...) pero esta vez

\footnotetext{
${ }^{30}$ Roger Bartra, El poder despótico burgués, México, Era, 1978, p. 70

${ }^{31}$ Karl Marx, El Capital, Tomo II, Vol. 1, Buenos Aires: Siglo XXI, 2006, p. 594

32 Karl Marx, Formaciones económicas precapitalistas, México: Siglo XXI, 2009c, p. 93

33 Vladimir I. Lenin, "La economía y la politica de la dictadura del proletariado" disponible en: https://www.marxists.org/espanol/lenin/obras/1910s/7xi1919.htm
} 
no tendría una representación caótica de un conjunto, sino una rica totalidad con múltiples determinaciones y relaciones ${ }^{34}$

Marx propone un recorrido metodológico claro, sintetizado en la "fórmula" concreto representado - abstracto - concreto pensado:

Lo concreto es concreto porque es la síntesis de múltiples determinaciones, por lo tanto, unidad de lo diverso. Aparece en el pensamiento como proceso de síntesis, como resultado, no como punto de partida, aunque sea el verdadero punto de partida, y, en consecuencia, el punto de partida también de la intuición y de la representación. En el primer camino, la representación plena es volatilizada en una determinación abstracta; en el segundo, las determinaciones abstractas conducen a la reproducción de lo concreto por el camino del pensamiento ${ }^{35}$

Ateniendo a este planteo de Marx, queda claro que la abstracción resulta un momento en el cual se distinguen -se abstraen- los atributos sustantivos de aquello que se investiga. "Las determinaciones más abstractas, cuando examinadas con mayor cuidado, siempre indican una concreta base histórica determinada (como es natural, ya que han sido abstraídas de ellas)" 36 . Un buen reflejo de esta labor de abstracción es posible apreciarlo en las tipologías comunitarias que presentan las Formen.

Ahora bien, luego de este momento de abstracción, Marx plantea un "viaje de retorno" hacia el concreto pensado, entendido como totalidad contradictoria, síntesis de múltiples determinaciones, superando el momento de la abstracción. Allí nos encontramos con un análisis propiamente histórico donde se da cuenta del devenir de las tendencias contradictorias que hacen a la reproducción social. Es, por lo tanto, en este momento de la dialéctica donde podemos ubicar tanto la categoría de modo de producción, como la de formación económica social. Retomamos en esta línea lo planteado por G. Lukács:

En Marx, el punto de partida no es el átomo, como en los viejos materialistas, ni el ser abstracto, como en Hegel. Todo lo existente debe poseer siempre carácter objetivo, debe ser siempre la parte más motora y móvil de un complejo concreto. Esto tiene dos consecuencias fundamentales. Primero, el entero ser es un proceso histórico; segundo, las categorías no son declaraciones de algo existente o en devenir, ni principios de formación (ideales) de la materia, sino formas motoras y móviles de la materia misma: "formas del ser, determinaciones de la existencia"37

En este sentido, sostenemos que quienes ven en la categoría de modo de producción una categoría abstracta ahistórica o una "formación ideal de la materia", parten en algún punto, de una confusión entre el modo de investigación y el modo de exposición; tal como señala Marx:

Ciertamente, el modo de exposición debe distinguirse, en lo formal, del modo de investigación. La investigación debe apropiarse pormenorizadamente de su objeto, analizar sus distintas formas de desarrollo y rastrear su nexo interno. Tan sólo después de consumada esa labor, puede exponerse adecuadamente el movimiento real. Si esto se logra y se llega a reflejar idealmente la vida de ese objeto es posible que al observador le parezca estar ante una construcción apriorística.

Mi método dialéctico no sólo difiere del de Hegel, en cuanto a sus fundamentos, sino que es su antítesis directa. Para Hegel el proceso del pensar, al que convierte incluso,

\footnotetext{
34 Marx, op.cit., 2009b, p. 21

${ }^{35}$ Idem

${ }^{36}$ Karl Marx, Friedrich Engels, Correspondencia, Buenos Aires: Cartago, 1957, p. 79

${ }_{37}$ Georg Lukács, Ontología del ser social. El trabajo, Buenos Aires: Herramienta, 2004, p. 36-37
} 
bajo el nombre de idea, en un sujeto autónomo, es el demiurgo de lo real; lo real no es más que su manifestación externa. Para mí, a la inversa, lo ideal no es sino lo material traspuesto y traducido en la mente humana. ${ }^{38}$

En esta misma línea, tras las lecturas simplificadoras de la dialéctica, reconocemos las huellas de cierto dualismo metodológico en el cual se produce una separación entre lo teórico y lo empírico, entre sujeto y objeto; separación que, por lo tanto, fija lo abstracto frente a lo concreto, eludiendo la explicación de su desarrollo. Frente a este planteo, se contrapone una mirada dialéctica entre sujeto y objeto, una comprensión de la complejidad entre las condiciones materiales y la acción de los actores, un entendimiento de la relación entre las categorías y la realidad:

Como en general en toda ciencia histórica, social, al observar el desarrollo de las categorías económicas hay que tener siempre en cuenta que el sujeto — la moderna sociedad burguesa en este caso- es algo dado tanto en la realidad como en la mente, y que las categorías expresan por lo tanto formas de ser, determinaciones de existencia, a menudo simples aspectos, de esta sociedad determinada, de este sujeto, y que por lo tanto, aun desde el punto de vista científico, su existencia de ningún modo comienza en el momento en que se comienza a hablar de ella como tal. ${ }^{39}$

La fuerte división entre sujeto y objeto propia del pensamiento burgués, esa distancia entre el sujeto que conoce y su objeto se funda en el propio fetichismo, en palabras de Lukács:

El carácter fetichista de las formas económicas, la cosificación de todas las relaciones humanas, (...) transforma los fenómenos de la sociedad y, junto con ellos, su apercepción. Así nacen hechos «aislados», complejos fácticos aislados, campos parciales con leyes propias (economía, política, etc.) que ya en sus formas inmediatas de manifestación parecen previamente elaborados para una investigación científica de esa naturaleza. (...) Mientras que, la dialéctica, que frente a esos hechos y esos sistemas parciales aislados y aisladores subraya la concreta unidad del todo, y descubre que esa apariencia es precisamente una apariencia -aunque necesariamente producida por el capitalismo-, parece una mera construcción.

La falta de cientificidad de ese método aparentemente tan científico consiste pues, en que ignora y descuida el carácter histórico de los hechos que le subyacen ${ }^{40}$

Quienes buscan la elaboración de teorías de cierto aspecto del todo social, fragmentando al objeto o postulando la existencia de esferas, se encuentran metodológicamente lejos de los planteos de Marx fundados en la dialéctica, en concebir la totalidad en su devenir histórico. Desde obras tan tempranas como los Manuscritos económico-filosóficos de 1844 como las Tesis sobre Fenerbach estas formulaciones son objeto de su preocupación:

El defecto fundamental de todo el materialismo anterior -incluyendo el de Feuerbaches que sólo concibe el objeto, la realidad, la sensorialidad, bajo la forma de objeto o de contemplación, pero no como actividad sensorial humana, como práctica, no de un modo subjetivo. De aquí que el lado activo fuese desarrollado por el idealismo, por oposición al materialismo, pero sólo en un modo abstracto, ya que el idealismo, naturalmente, no conoce la actividad real, sensorial, como tal. Feuerbach quiere objetos sensibles (...) pero tampoco él concibe la actividad humana como una actividad objetiva. (...) Por

\footnotetext{
38 Marx, op.cit., 2008, p. 19

${ }^{39}$ Marx, op.cit., 2009b, p. 27

40 Georg Lukács, Historia y conciencia de clase, Madrid: Ediciones Orbis, 1985, p. 51
} 
tanto, no comprende la importancia de la actividad "revolucionaria", "prácticocrítica" 41

La cuestión metodológica nuevamente es puesta en primer plano. Si se comprende de manera abstracta los modos de producción, si se compartimenta la realidad en esferas y se observa al modo de producción como "base económica", se pierde pues de vista la propia acción práctica, la actividad revolucionaria capaz de transformar las condiciones materiales aparece como factor ajeno y externo. Aquello que no se puede evidenciar es la relación entre la forma que adquiere la lucha de clases en un modo de producción determinado y las capacidades, modos y posibilidades que esta acción tiene de transformarlo. En las concepciones estructuralistas, en suma, se dificulta pensar el propio cambio histórico. Al observarse estructuras estancas y compartimentadas, donde la acción de los sujetos se pierde por completo de vista, no hay posibilidad de transformación: lo que es no puede dejar de ser. Volvemos una vez más a la propia visión de la historia de Marx. Al respecto en La Ideología Alemana, Marx y Engels sostienen:

(...) cada generación transfiere a la que le sigue un conjunto de fuerzas productivas, capitales y circunstancias, que, aunque por una parte sean modificados por la nueva generación, por otra parte le dictan sus propias condiciones de vida y le imprimen un desarrollo determinado, un carácter especial; de que, por lo tanto, las circunstancias hacen al hombre en la misma medida en que éste hace las circunstancias ${ }^{42}$

Encontramos pues, en las formulaciones de Marx una determinación material: el sujeto es producto de una dinámica estructural, pero a su vez ejerce una actividad que genera prácticas estructurantes y desestructurantes; lejos estamos del determinismo ciego que propugna el estalinismo y las versiones estructuralistas de los años 70', a las cuales se asocia la categoría de modo de producción como objeto teórico. Esto mismo está puesto de manifiesto también en las Tesis sobre Feuerbach:

\begin{abstract}
La teoría materialista de que los hombres son producto de las circunstancias y de la educación, y de que, por tanto, los hombres modificados son producto de circunstancias distintas y de una educación modificada, olvida que son los hombres, precisamente, los que hacen que cambien las circunstancias y que el propio educador necesita ser educado. (...) La coincidencia de la modificación de las circunstancias y de la actividad humana sólo puede concebirse y entenderse racionalmente como práctica revolucionaria ${ }^{43}$
\end{abstract}

El evolucionismo unilineal y el determinismo no se corresponden con la visión de la historia de Marx; por el contrario, en ella la historia resulta de la práctica revolucionaria, no entendida de manera aislada sino comprendida como lucha de clases cuya forma y posibilidades están determinadas e inscriptas en una totalidad contradictoria, un determinado modo de producción.

Las aproximaciones antidialécticas suelen presentar la historia como una sucesión evolutiva de modos de producción. Estas lecturas pierden de vista que la indagación de Marx apunta a los supuestos históricos de la relación capital/trabajo, en pos de comprender la dinámica del modo de producción capitalista con el objetivo de su transformación revolucionaria; lejos por ende de la concepción transhistórica de tendencias que evolucionan hacia un progreso universal. En los propios Grundrisse este interés por el estudio de los modos de producción pasados queda explicitado:

\footnotetext{
${ }^{41}$ Karl Marx, "Tesis sobre Feuerbach", Obras Escogidas, Tomo IV, Buenos Aires: Ciencias del Hombre, 1973, p. 9

42 Marx, Engels, op.cit., 1973a , p.34

${ }^{43}$ Marx, op.cit., 1973, p. 9
} 
La sociedad burguesa es la más compleja y desarrollada organización histórica de la producción. Las categorías que expresan sus condiciones y la comprensión de su organización permiten al mismo tiempo comprender la organización y las relaciones de producción de todas las formas de sociedad pasadas, sobre cuyas ruinas y elementos ella fue edificada y cuyos vestigios, aún no superados, continúa arrastrando, a la vez que meros indicios previos han desarrollado en ella su significación plena, etc. La anatomía del hombre es una clave para la anatomía del mono. Por el contrario, los indicios de las formas superiores en las especies animales inferiores pueden ser comprendidos sólo cuando se conoce la forma superior. ${ }^{44}$

Se trata pues, de rastrear en las sociedades precapitalistas los supuestos históricos de la relación capital/trabajo y por ende, estudiarlas a la luz del capitalismo. Esto no implica una visión teleológica de la historia ${ }^{45}$ en la cual el capitalismo es su fin último, sino partir de un método genético estructural: comprender la estructura y dinámica capitalista a partir de su génesis histórica entendiendo cómo y qué posibilitó su desarrollo para analizar sus contradicciones y superarlas a través de una práctica revolucionaria. Es, en el marco de esta concepción de la historia, que se inscriben las nociones de modo de producción y formación económica social, y se pone en relieve la visión de totalidad dialéctica.

En esta visión, ambas categorías permiten ver la complejidad desde distintas perspectivas: el modo de producción desde la lógica de reproducción de la totalidad involucrada en todos los aspectos de la vida, mientras que, la formación económica social pone en evidencia la existencia de diversas formas -asociadas a otros modos de producción- cuyo contenido está determinado por la totalidad, así como dar cuenta de los momentos transicionales. A lo largo del artículo hemos procurado revalorizar la obra de Marx, recuperando su visión de totalidad y la dialéctica como método. Esperamos que tales formulaciones se conviertan en aportes para futuras investigaciones y reflexiones.

\section{Bibliografía}

- Louis Althusser, Ideología y aparatos ideológicos del Estado. Freudy Lacan, Buenos Aires, Nueva Visión, 1984.

- Louis Althusser, Étienne Balibar, Para leer El Capital, México, Siglo XXI, 2004

- Perry Anderson, Transiciones de la antigüedad al feudalismo, México, Siglo XXI, 2007

- $\quad$ Perry Anderson, El Estado absolutista, México, Siglo XXI, 2009

- Jairus Banaji, Theory as History. Essays on Modes of production and exploitation, Boston, Brill, 2010

- Roger Bartra, El poder despótico burgués, México, Era, 1978

- Robert Brenner, "Estructura de clases agraria y desarrollo económico en la Europa preindustrial" en Aston, T. H y Philpin, C.H. E (comps) El debate Brenner, Barcelona, Crítica, 1987

- Maurice Dobb, Estudios sobre el desarrollo del capitalismo, México, Siglo XXI, 2005

\footnotetext{
${ }^{44}$ Marx, op.cit.,2009b, p. 26

45 Esta ha sido una crítica atribuida al marxismo, como lo sostiene Wickham: "La teleología del desarrollo del feudalismo al capitalismo estaba presente en Marx, y ha sido dominante en todas las tendencias de la historia económica que plantean la "excepcionalidad" europea (o inglesa), como ya he señalado. Estas teleologías creo que distorsionan las complejidades y singularidad de los procesos históricos reales y, en particular, terminan privilegiando un conjunto de pautas económicas como portadoras del desarrollo, y condenando a otras como "estancadas" o "bloqueadas", de un modo recargado y (con frecuencia) desagradablemente triunfalista" (En: Chris Wickham, "Memorias del subdesarrollo: ¿Qué ha hecho el marxismo por la historia medieval, y qué puede hacer aún?, Anales de Historia Antigua, Medieval y Moderna, Bs. As., no 41, 2009).

Sin embargo, este tipo de críticas esconde un conocimiento parcial de la obra de Marx que -como mencionamos- no poseía una visión teleológica y por el contrario, ha discutido fuertemente tal lectura de sus reflexiones: "mi esbozo histórico de la génesis del capitalismo en el Occidente europeo en una teoría histórico-filosófica de la marcha general que el destino le impone a todo pueblo, cualesquiera sean las circunstancias históricas en que se encuentre, a fin de que pueda terminar por llegar a la forma de la economía que le asegure, junto con la mayor expansión de las potencias productivas del trabajo social, el desarrollo más completo del hombre" (Marx, Engels, op.cit.,1957, p. 237).
} 
- Christine Glucksman, "Modo de producción, formación económica y social, y teoría de la transición a propósito de Lenin", en Luporini, C; Sereni, E., El concepto de "formación económico-social", Buenos Aires, Ediciones Pasado y Presente, Siglo XXI, 1973.

- Maurice Godelier, Economía, fetichismo y religión en las sociedades primitivas, Madrid: Siglo XXI, 1974

- Marta Harnecker, Los conceptos elementales del materialismo histórico, Buenos Aires: Siglo XXI, 2005.

- Barry Hindess, Paul Hirst, Los modos precapitalistas de producción Barcelona: Ediciones Península, 1979.

- Eric Hobsbawm, "Introducción” en Marx, Karl. Formaciones económicas precapitalistas, México: Siglo XXI, 2009

- Antonio Labriola, En memoria del Manifiesto Comunista, 1964

- Vladimir I. Lenin, "La economía y la política de la dictadura del proletariado" disponible en: https://www.marxists.org/espanol/lenin/obras/1910s/7xi1919.htm

- Vladimir I. Lenin, El desarrollo del capitalismo en Rusia, En: Obras completas, Vol. III. Buenos Aires, Cártago, 1957.

- Vladimir I. Lenin, ¿Quiénes son los "amigos del pueblo" y cómo luchan contra los socialdemócratas?, Buenos Aires: Editorial Ateneo, 1973

- Georg Lukács, Historia y conciencia de clase, Madrid: Ediciones Orbis, 1985.

- Georg Lukács, Ontología del ser social. El trabajo, Buenos Aires: Herramienta, 2004

- Cesare Luporini, Emilio Sereni, El concepto de "formación económico-social", Buenos Aires: Ediciones Pasado y Presente, Siglo XXI, 1973

- Karl Marx, “Tesis sobre Feuerbach”, Obras Escogidas, Tomo IV, Buenos Aires: Ciencias del Hombre, 1973

- Karl Marx, El Dieciocho Brumario de Luis Bonaparte, Buenos Aires: Andrómena, 2004

- Karl Marx, El Capital, Tomo II, Vol. 1, Buenos Aires: Siglo XXI, 2006

- Karl Marx, Manuscritos económico-filosóficos, Buenos Aires: Colihue, 2006

- Karl Marx, El Capital, Tomo I, Vol. 1, Buenos Aires: Siglo XXI, 2008

- Karl Marx, El Capital, Tomo III, Vol. 8, México: Siglo XXI, 2009a

- Karl Marx, Elementos fundamentales para la crítica de la economía política (Grundrisse) 1857-1858, México: Siglo XXI, 2009b

- Karl Marx, Formaciones económicas precapitalistas, México: Siglo XXI, 2009c

- Karl Marx, Contribución a la Crítica de la Economía Política, México, Siglo XXI, 2011a

- Karl Marx, El Capital Libro I Capitulo VI (inédito), México: Siglo XXI, 2011b

- Karl Marx, Friedrich Engels, Correspondencia, Buenos Aires: Cartago, 1957

- Karl Marx, Friedrich Engels, "Feuerbach, contraposición entre la concepción materialista y la idealista (Capítulo I de La Ideología Alemana)", Obras Escogidas, Tomo IV, Buenos Aires: Ciencias del Hombre, $1973 \mathrm{a}$

- Karl Marx, Friedrich Engels, Correspondencia, Buenos Aires: Cartago, 1973b

- Ellen Meiksins Wood, Democracia contra capitalismo,_México: Siglo XXI, 2000

- Charles Post, The American Road to Capitalism, studies in class-structure, economic development, and political conflict, 1620-1877, Boston: Historical Materialism Series 28, Brill, 2011

- Nicos Poulantzas, Poder político y clases sociales en el Estado capitalista, México: Siglo XXI, 2007

- Nicos Poulantzas, Las clases sociales en el capitalismo actual, México: Siglo XXI, 2016

- León Trotsky, Historia de la Revolución Rusa, Madrid: Sarpe, 1985

- Pierre Vilar, Economía, derecho, bistoria, Barcelona, Ariel, 1983

- Chris Wickham, "Memorias del subdesarrollo: ¿Qué ha hecho el marxismo por la historia medieval, y qué puede hacer aún?, Anales de Historia Antigua, Medievaly Moderna, Bs. As., n 41, 2009 